\title{
Zoledronic acid modulates human osteosarcoma cells proliferation via GSK-3 $\beta$ activation
}

\author{
S. $\mathrm{LI}^{1,2}$, J. J. $\mathrm{LI}^{1, *}$ \\ ${ }^{1}$ Department of Orthopedics, Shengjing Hospital of China Medical University, Shenyang, 110004 Liaoning Province, China; ${ }^{2}$ Department of \\ Orthopedics, Central Hospital of Sujiatun District, Shenyang, 110101 Liaoning Province, China.
}

*Correspondence: lij2046@126.com

Received November 28, 2018 / Accepted April 10, 2019

\begin{abstract}
Zoledronate is clinically used for preventing skeletal complications of osteoporosis and specific types of cancer associated with bone metastasis. Zoledronate inhibits osteoclast development and induces osteoclast apoptosis, thereby reducing bone lysis. Zoledronic acid (ZOL) plays a key role in treating osteosarcoma (OS) and improving the prognosis of patients with OS; however, its mechanism remains unclear. The effect of zoledronic acid on osteosarcoma cells was examined, and MTT was performed to determine the effect of ZOL on osteosarcoma cell proliferation. Cells were treated with $0,25,50$, 100 or $200 \mu \mathrm{M} Z \mathrm{ZOL}$ for $24 \mathrm{~h}, 48 \mathrm{~h}$ and $72 \mathrm{~h}$. p-AKT/AKT and p-GSK-3 $\beta / G S K-3 \beta$ expression levels were checked by western blotting. Further study compared $100 \mu \mathrm{M} Z \mathrm{ZOL}$ alone for $48 \mathrm{~h}, \mathrm{Li}_{2} \mathrm{CO}_{3}(1 \mathrm{mM})$ alone and $\mathrm{ZOL}(100 \mu \mathrm{M}) \mathrm{plus}^{\mathrm{Li}} \mathrm{CO}_{3}(1 \mathrm{mM})$ with no treatment (control). The effects of GSK-3 $\beta$ on ZOL-induced apoptosis among these groups were characterized by flow cytometry, MTT assay, transmission electron microscopy (TEM) and western blot. In this study, we found that the proliferation of MG-63 cells was significantly decreased after treatment with 25, 50, 100 or $200 \mu \mathrm{M}$ ZOL for 48 and $72 \mathrm{~h}$ compared to untreated control cells. The expression levels of p-AKT/AKT and p-GSK-3 $\beta / G S K-3 \beta$ in MG-63 cells and U-2 OS cells were inhibited by ZOL in both a dose- and time-dependent manner. Significant decreases in the expression of Cyclin D1, $\beta$-Catenin, and c-Myc were observed in the groups that underwent ZOL treatment. Additionally, compared to ZOL $(100 \mu \mathrm{M})$ treatment alone, co-treatment with $\mathrm{ZOL}(100 \mu \mathrm{M})$ and $\mathrm{Li}_{2} \mathrm{CO}_{3}(1 \mathrm{mM})$ rescued cell proliferation and restored a significant percentage of apoptotic cells. Our study suggests that the specific mechanism by which ZOL affects apoptosis of osteosarcoma cells is through the AKT/GSK- $3 \beta / \beta$-Catenin signaling pathway.
\end{abstract}

Key words: zoledronic acid, osteosarcoma, AKT, Wnt, GSK-3 $\beta$

Osteosarcoma (OS) is a primary bone-derived tumor that mostly develops among children or adolescents and approximately $20 \%$ of patients are diagnosed with metastases. Data from the American Cancer Society show that the five-year survival rate of patients with OS after chemotherapy is approximately $70 \%$, while the five-year survival rate of patients with tumor metastases is greatly reduced to approximately 20\% (http://www.cancer.org/cancer/osteosarcoma). Thus, effective treatments that control OS tumor growth and tumor cell proliferation are needed.

Zoledronic acid (ZOL) is a third-generation bisphosphonate (BP). Zoledronate inhibits osteoclast development and induces osteoclast apoptosis, thereby reducing bone lysis. In vitro experimental results show that $\mathrm{ZOL}$ can inhibit OS cell proliferation by inducing apoptosis or blocking angiogenesis [1-3]. Moreover, many studies have shown that ZOL exerts antiproliferative and proapoptotic effects on a variety of cancer cells $[4,5]$ and has the potential to be an effective treatment against cancer.

The Wnt signaling pathway is involved in the differentiation and reprogramming of bone marrow stromal cells, which affect the differentiation of osteoblasts and osteoclasts and regulate bone repair. This pathway also plays a key role in the growth, regeneration and remodeling of bone. Canonical pathway that is induced by Wnt signaling pathway is the $\beta$-Catenin-dependent pathway. Wnt proteins bind to Frizzled (Fzd) and low-density lipoprotein receptor related protein $5 / 6$ (LRP-5/6) to induce the accumulation of $\beta$-Catenin in nucleus to form complexes that mediate the transcriptional induction of target genes and regulate a diverse array of biological processes [6,7]. In the absence of Wnt ligands, cytoplasmic $\beta$-Catenin is phosphorylated through a complex containing GSK-3 $\beta / \mathrm{APC} / \mathrm{Axin}$ and then is degraded. Wnt pathway activation is observed in both human primary 
OS cells and established OS cell lines [8]. As previously described, OS metastasis incidence and cancer-free survival are related to LRP5 expression [9].

The PI3K/AKT pathway is another key signaling pathway involved in the pathogenesis of OS. The PI3K/AKT pathway is known to regulate OS cell proliferation, invasion, metastasis and angiogenesis. In an in vivo genome-wide screen, analysis of pooled shRNAs shows that mTOR and PI3K are required for OS tumor cell proliferation and survival [10]. In addition, AKT pathway activation is present in all OS-related cell lines [11].

ZOL plays a role in treating OS and improving the prognosis of patients with OS; however, its mechanism remains unclear. Studies have shown that ZOL downregulates the mRNA expression of Wnt pathway members, such as Wnt5a, FZD5 and DKK1, in bone and in prostate cancer cells (PC3) [12]. ZOL is reported to inhibit the growth of the breast cancer cell lines MCF-7 and MDA-MB-231 through inhibiting the AKT-mTOR pathway [13]. In the human colon cancer cell line HCT116, the ZOL derivative $\mathrm{M}_{4} \mathrm{IDP}$ inhibits cell proliferation by increasing the expression of PTEN, which inhibits the PI3K/AKT/mTOR pathway [14]. The abovementioned results suggest that ZOL can regulate OS cell migration, proliferation and apoptosis by regulating the Wnt and PI3K/AKT/mTOR pathways. GSK-3 $\beta$ is an important downstream molecule of the PI3K/AKT pathway, and its activation is regulated by this pathway. Therefore, ZOL can induce apoptosis in the mouse macrophage cell line RAW264.7 by activating GSK-3 $\beta$ [15].

We chose MG-63 cells which have been extensively studied and U-2 OS cells which have the most obvious effect of zoledronic acid as the research objects. Our study suggests that ZOL possesses antiproliferative and cytotoxic activities by inducing apoptosis in the human osteosarcoma cell lines MG-63 and U-2 OS. The inhibition of the PI3K/AKT pathway caused by ZOL treatment could activate GSK-3 $\beta$, which would result in downregulation of the Wnt $/ \beta$-Catenin pathway to inhibit OS cell proliferation. This chain of events eventually results in OS cell apoptosis and shows great potential in OS tumor treatment.

\section{Materials and methods}

Cell culture. The human osteosarcoma cell lines MG-63 and U-2 OS were purchased from the Cells Resource Center of the Shanghai Institutes for Biological Sciences, Chinese Academy of Sciences (Shanghai; China). Cells were cultured in Dulbecco's modified Eagle's medium (DMEM; HyClone, UT, USA) supplemented with $10 \%$ (v/v) fetal bovine serum (FBS; Gibco Life Technologies, Carlsbad, CA, USA) and 1\% (v/v) penicillin-streptomycin (HyClone) at $37^{\circ} \mathrm{C}$ in a humidified atmosphere containing 5\% $\mathrm{CO}_{2}$.

Cell proliferation assay. The MTT assay was performed to determine the effect of ZOL on the proliferation of MG63 cells. Briefly, cells were seeded in a 96-well culture plate at a density of $10 \times 10^{3}$ cells per well and then treated with 25,50 , 100 or $200 \mu \mathrm{M}$ of ZOL for 24,48 and $72 \mathrm{~h}$. After drug treatment, 3-[4,5-dimethylthiazol-2-yl]-2,5-diphenyl tetrazolium bromide (MTT; Sigma, St. Louis, MO, USA) was added at a final concentration of $0.5 \mathrm{mg} / \mathrm{ml}$, and cells were incubated for two hours at $37^{\circ} \mathrm{C}$ in the dark. The resulting formazan product was dissolved in dimethyl sulfoxide (DMSO; Sigma), and the optical density (OD) values were measured using a microplate reader (SpectraMax 250; Molecular Devices, CA, USA) at a wavelength of $490 \mathrm{~nm}$.

Flow cytometry assay of cell apoptosis. After cells underwent a $48 \mathrm{~h}$ preincubation with $\mathrm{ZOL}$ or $\mathrm{Li}_{2} \mathrm{CO}_{3}$, they were washed with ice-cold PBS, trypsinized, and then resuspended in $1 \times$ binding buffer $[10 \mathrm{mM} H E P E S / N a O H$ ( $\mathrm{pH} 7.4), 140 \mathrm{mM} \mathrm{NaCl}$ and $2.5 \mathrm{mM} \mathrm{CaCl}_{2}$ ] at $1 \times 10^{6} \mathrm{cells} / \mathrm{ml}$. Aliquots $(100 \mu \mathrm{l})$ of the cell suspension were mixed with $5 \mu \mathrm{l}$ of annexin V/fluorescein isothiocyanate (FITC) (BD Biosciences, NJ, USA) and $10 \mu \mathrm{l}$ of propidium iodide (PI) stock solution $(50 \mu \mathrm{g} / \mathrm{ml}$ in PBS). The mixture was gently vortexed and incubated at room temperature for $15 \mathrm{~min}$ in the dark. After incubation, $400 \mu \mathrm{l}$ of $1 \times$ binding buffer was added to each sample and the samples were analyzed on a FACScan ${ }^{\text {tw }}$ flow cytometer (BD Biosciences). A minimum of 10000 cells was counted for each sample and data were analyzed using CellQuest $^{\text {tw }}$ software (BD Biosciences).

Transmission electron microscopy (TEM). Treated MG-63 cells were fixed with $0.15 \mathrm{M}$ sodium cacodylate buffer containing $2 \mathrm{mM} \mathrm{CaCl}_{2}$ and $2 \%$ glutaraldehyde. Then, the cell suspension was incubated for $30 \mathrm{~min}$ in $1 \%$ osmium tetraoxide and $60 \mathrm{~min}$ in $1 \%$ uranyl acetate. The specimens were dehydrated in increasing concentrations of ethanol, embedded in epoxypropane and polymerized at $60^{\circ} \mathrm{C}$ for $48 \mathrm{~h}$. Ultrathin sections were prepared and examined under a HITACHI H-7650 transmission electron microscope (HITACHI, Tokyo, Japan).

Western blot analysis. Cells were scraped off $6 \mathrm{~cm}$ dishes and suspended in RIPA lysis buffer $(50 \mathrm{mM}$ Tris- $\mathrm{HCl}$, $150 \mathrm{mM} \mathrm{NaCl}, 0.25 \%(\mathrm{v} / \mathrm{v})$ sodium deoxycholate, $1 \%(\mathrm{v} / \mathrm{v})$ Triton X-100, pH 7.4) on ice. After the cell lysate was centrifuged $(13000 \times \mathrm{g})$ at $4^{\circ} \mathrm{C}$ for $15 \mathrm{~min}$, the protein concentration was determined by the Bio-Rad protein assay (Bio-Rad, Hercules, CA, USA). Protein lysates $(50 \mu \mathrm{g})$ were separated in $12 \%(\mathrm{v} / \mathrm{v})$ sodium dodecyl sulfate (SDS)-polyacrylamide gels and then transferred to a $0.22 \mu \mathrm{m}$ polyvinylidene fluoride membrane (Millipore, Bedford, MA, USA). The membrane was blocked with $5 \%(\mathrm{w} / \mathrm{v})$ milk in $1 \mathrm{x}$ TBST buffer $(10 \mathrm{mM}$ Tris-base, $150 \mathrm{mM} \mathrm{NaCl}, 0.05 \%(\mathrm{v} / \mathrm{v})$ Tween 20; $\mathrm{pH} 7.4)$ for one hour at room temperature. Primary antibodies targeting AKT, p-AKT, GSK-3 $\beta$, p-GSK-3 $\beta$ (Ser9), c-Myc, $\beta$-Catenin, $\beta$-actin, and Cyclin D1 (Cell Signaling Technology, MA, USA) were then incubated with the membranes at $4^{\circ} \mathrm{C}$ overnight. Membranes were washed with $1 \mathrm{x}$ TBST three times and then incubated with horseradish peroxidase (HRP)-conjugated secondary antibodies for two hours at room temperature. Following additional TBST washes, visualization of the 
protein bands was carried out using an enhanced chemiluminescence kit (ECL; Thermo Fisher Scientific, MA, USA).

Statistical analysis. All experiments were repeated at least three times with independent treatments, each of which showed no significantly different results. The data were analyzed by Student's t-test or one-way ANOVA with Bonferroni test using the SPSS statistical software package. All results are expressed as the mean \pm SEM. For all analyses, a two-sided p-value of less than 0.05 was deemed statistically significant.

\section{Results}

Effect of different doses of ZOL on MG-63 cell proliferation. The antiproliferative activity of ZOL on MG-63 cells was assessed through photomicrographs and the MTT assay. As shown in Figure 1, the proliferation of MG-63 cells was inhibited by ZOL in both a dose- and time-dependent manner. The proliferation of MG-63 cells significantly decreased when treated with $25,50,100$ or $200 \mu \mathrm{M}$ of $\mathrm{ZOL}$ for 48 and $72 \mathrm{~h}$ compared to the untreated controls $(\mathrm{p}<0.01)$.
The results suggested the high inhibitory potency and the sustained inhibitory effect of ZOL on MG-63 cells.

Effect of ZOL on the AKT/GSK-3 $\beta$ pathway in MG-63 and U-2 OS cells. Because ZOL demonstrated antiproliferative and antimigration activities towards MG- 63 cells, we next examined the underlying inhibitory effect of ZOL. As previously described, the AKT/GSK-3 $\beta$ pathway plays a central role in cell survival and apoptosis. We evaluated the levels of phosphorylated AKT and phosphorylated GSK-3 $\beta$, which represent the AKT and GSK-3 $\beta$ activation state, respectively, by western blot analysis. As shown in Figure 2, the ratio of p-AKT/AKT and p-GSK-3 $\beta / G S K-3 \beta$ expression in MG-63 cells was reduced by ZOL in both a dose- and time-dependent manner $(\mathrm{p}<0.01$ and $\mathrm{p}<0.05$, respectively). As shown in Figure 3, we obtained similar results with U-2 OS cells $(\mathrm{p}<0.01$ and $\mathrm{p}<.05$, respectively). The ratio of $\mathrm{p}-\mathrm{AKT} / \mathrm{AKT}$ and $\mathrm{p}-\mathrm{GSK}-3 \beta / \mathrm{GSK}-3 \beta$ expression significantly decreased in the presence of higher concentrations of ZOL. These results suggest that $\mathrm{ZOL}$ inhibited $\mathrm{PI} 3 \mathrm{~K} / \mathrm{AKT}$ which in turn activated GSK-3 $\beta$, is related to the ZOL-induced cytotoxic effects.

\section{A}
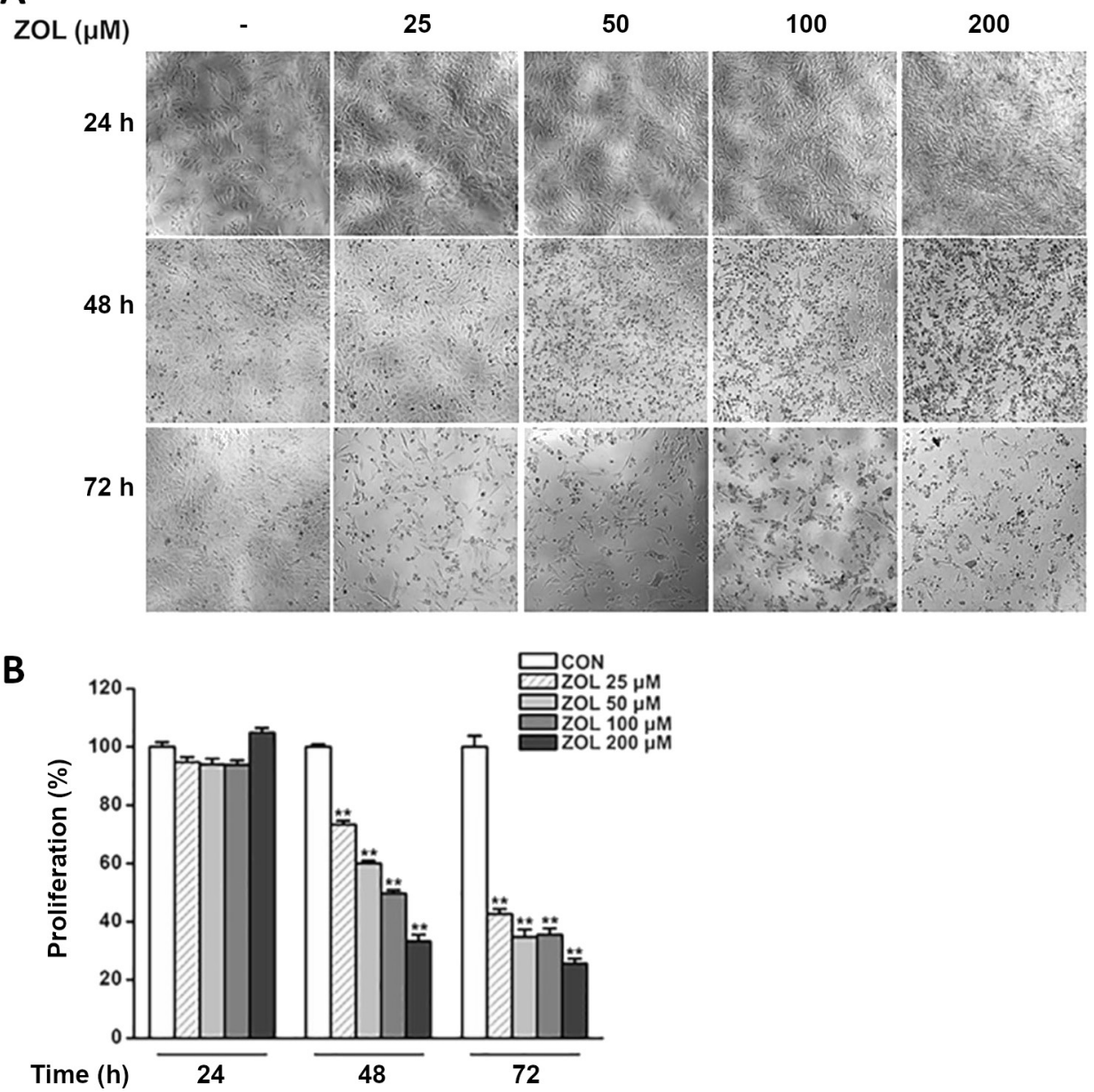

Figure 1. Effects of different doses of ZOL on MG-63 cell proliferation as evaluated by photomicrographs (A) and the MTT assay (B). Data are presented as the mean \pm SEM of 3 determinations, ${ }^{* *}: \mathrm{p}<0.01$ and ${ }^{*}: \mathrm{p}<0.05$ vs. CON group. 
A

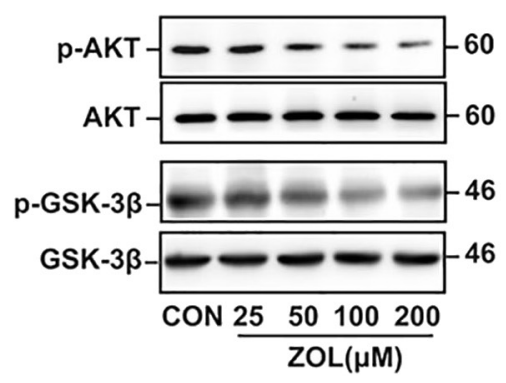

B

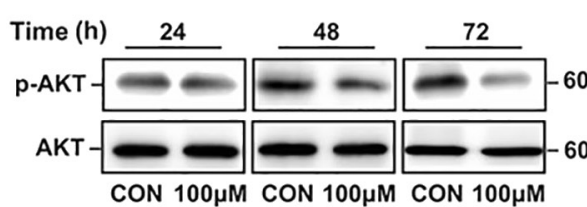

C

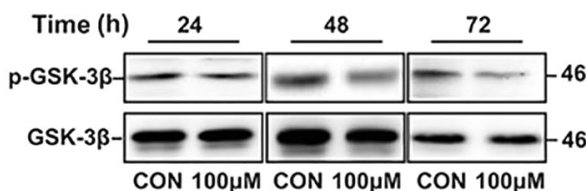

Effect of ZOL on the Wnt/ $\beta$-Catenin pathway in MG-63 and U-2 OS cells. To investigate whether ZOL-induced inactivation of the AKT/GSK-3 $\beta$ pathway also inhibits the Wnt $/ \beta$-Catenin pathway, we examined the expression of Cyclin D1, $\beta$-Catenin, and c-Myc in MG-63 and U-2 OS cells. The Wnt/ $\beta$-Catenin pathway is known to be closely associated with the migration and apoptosis of OS [16]. In the absence of Wnt ligands, cytoplasmic $\beta$-Catenin is phosphorylated through a complex containing GSK-3 $\beta / A P C / A x i n$, after which it is degraded. To demonstrate the role of GSK-3 $\beta$ in the effect of ZOL on the Wnt/ $\beta$-Catenin pathway, in our study we used $\mathrm{Li}_{2} \mathrm{CO}_{3}(1 \mathrm{mM})$, a GSK-3 $\beta$ inhibitor for the
Wnt $/ \beta$-Catenin pathway. As shown in Figures 4 and 5, significant decreases were observed in Cyclin D1, $\beta$-Catenin and c-Myc expression among the MG-63 and U-2 OS cells that underwent $Z O L$ treatment $(\mathrm{p}<0.01$ and $\mathrm{p}<0.05$, respectively). ZOL-induced inhibition of the Wnt/ $\beta$-Catenin pathway was restored by pretreatment with $\mathrm{Li}_{2} \mathrm{CO}_{3}(1 \mathrm{mM})$. These results suggested that $\mathrm{ZOL}$ inhibits the Wnt/ $\beta$-Catenin pathway and that GSK-3 $\beta$ mediates ZOL-induced inhibition of the Wnt $/ \beta$ Catenin pathway.

Effect of GSK-3 $\beta$ on ZOL-induced MG63 and U-2 OS cells proliferation and apoptosis. To determine whether GSK- $3 \beta$ could mediate the antiproliferative activity of ZOL, 
A

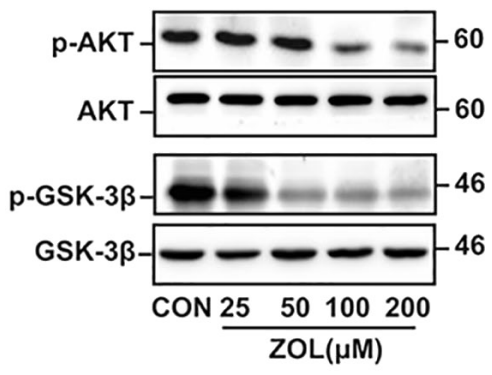

B

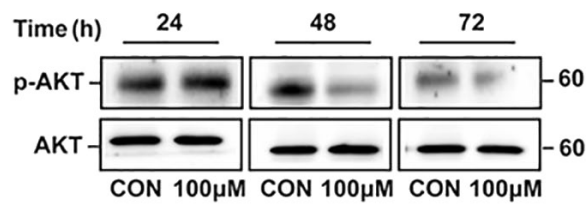

C

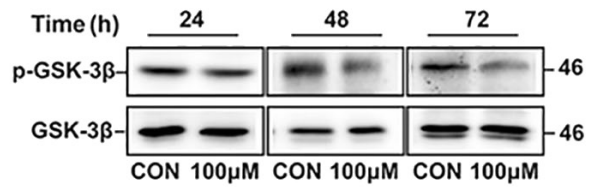

we assessed the effect of $\mathrm{Li}_{2} \mathrm{CO}_{3}$ on MG-63 cell proliferation. As shown in Figure 6C, compared to $\mathrm{ZOL}$ treatment alone, co-treatment with $\mathrm{ZOL}$ and $\mathrm{Li}_{2} \mathrm{CO}_{3}$ partially rescued cell proliferation. We further investigated the effects of GSK- $3 \beta$ on ZOL-induced apoptosis by flow cytometry using annexin V-FITC/PI staining. As shown in Figures 6A, B and Figures $7 \mathrm{~A}, \mathrm{~B}$, the apoptotic rate of cells treated with ZOL was significantly higher than that of untreated cells or cells treated with $\mathrm{Li}_{2} \mathrm{CO}_{3}$. Furthermore, co-treatment with $\mathrm{Li}_{2} \mathrm{CO}_{3}$ restored the apoptotic rate of ZOL-treated cells. As shown in Figure 8, the untreated cells or cells treated with $\mathrm{Li}_{2} \mathrm{CO}_{3}$ presented an integrated unclear membrane, relatively
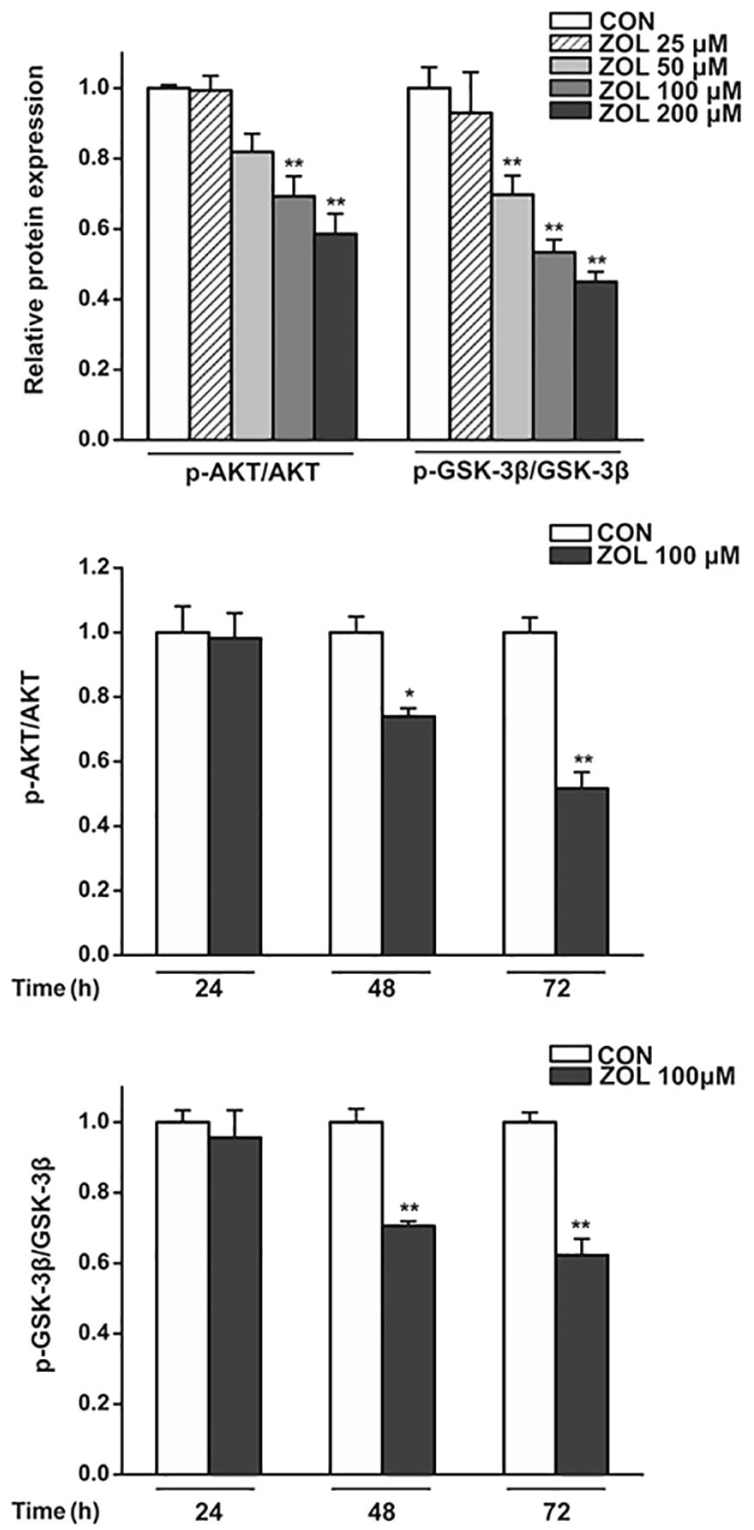

Figure 3. Effects of different doses and durations of ZOL administration on AKT phosphorylation (A), (B) and GSK-3 $\beta$ phosphorylation (A), (C) in U-2 OS cells. Data are presented as the mean \pm SEM of 3 determinations, ${ }^{* *}: \mathrm{p}<0.01$ and ${ }^{*}: \mathrm{p}<0.05$ vs CON group.

homogeneous chromatin and extensive membrane interdigitations and microvilli. Following treatment with ZOL, MG-63 cells were characterized by condensation into dense granules or blocks, migration of nuclear chromatin, and the formation of apoptotic bodies and numerous vacuoles in the cytoplasm; furthermore, membrane microvilli were also observed. MG-63 cells pretreated with $\mathrm{Li}_{2} \mathrm{CO}_{3}$ presented an appearance similar to that of cells treated with $\mathrm{ZOL}$ alone. Concurrently, there were a number of membrane microvilli visible. These results suggest that ZOL modulates the proliferation and apoptosis of MG-63 and U-2 OS cells via GSK-3 $\beta$ activation. 

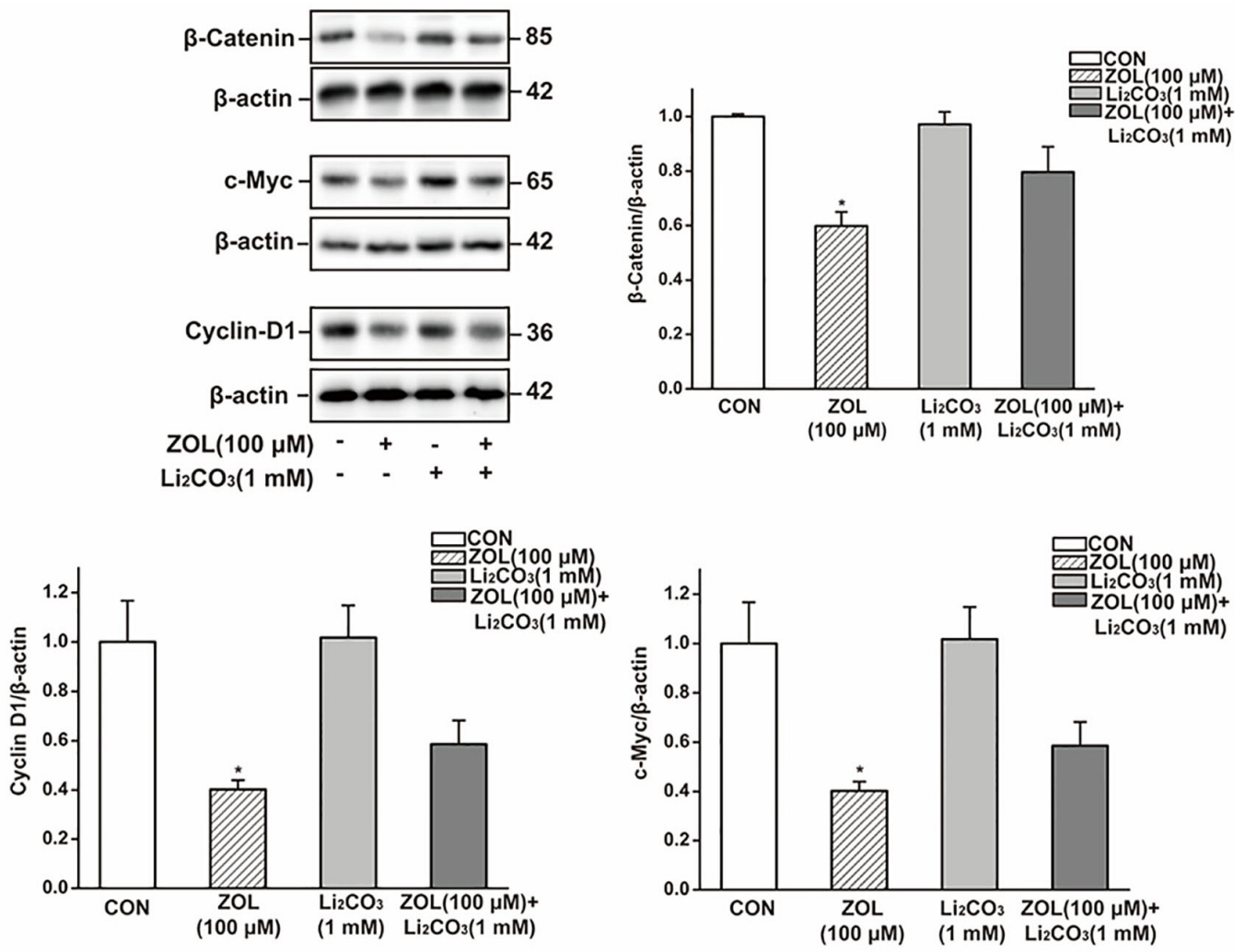

Figure 4. Effects of $\mathrm{ZOL}$ and $\mathrm{Li}_{2} \mathrm{CO}_{3}$ administration on the protein expression levels of $\beta$-Catenin, c-Myc and Cyclin D1 in MG-63 cells. Data are presented as the mean \pm SEM of 3 separate experiments, ${ }^{* *}: \mathrm{p}<0.01$ and ${ }^{*}: \mathrm{p}<0.05$ vs. the CON group.
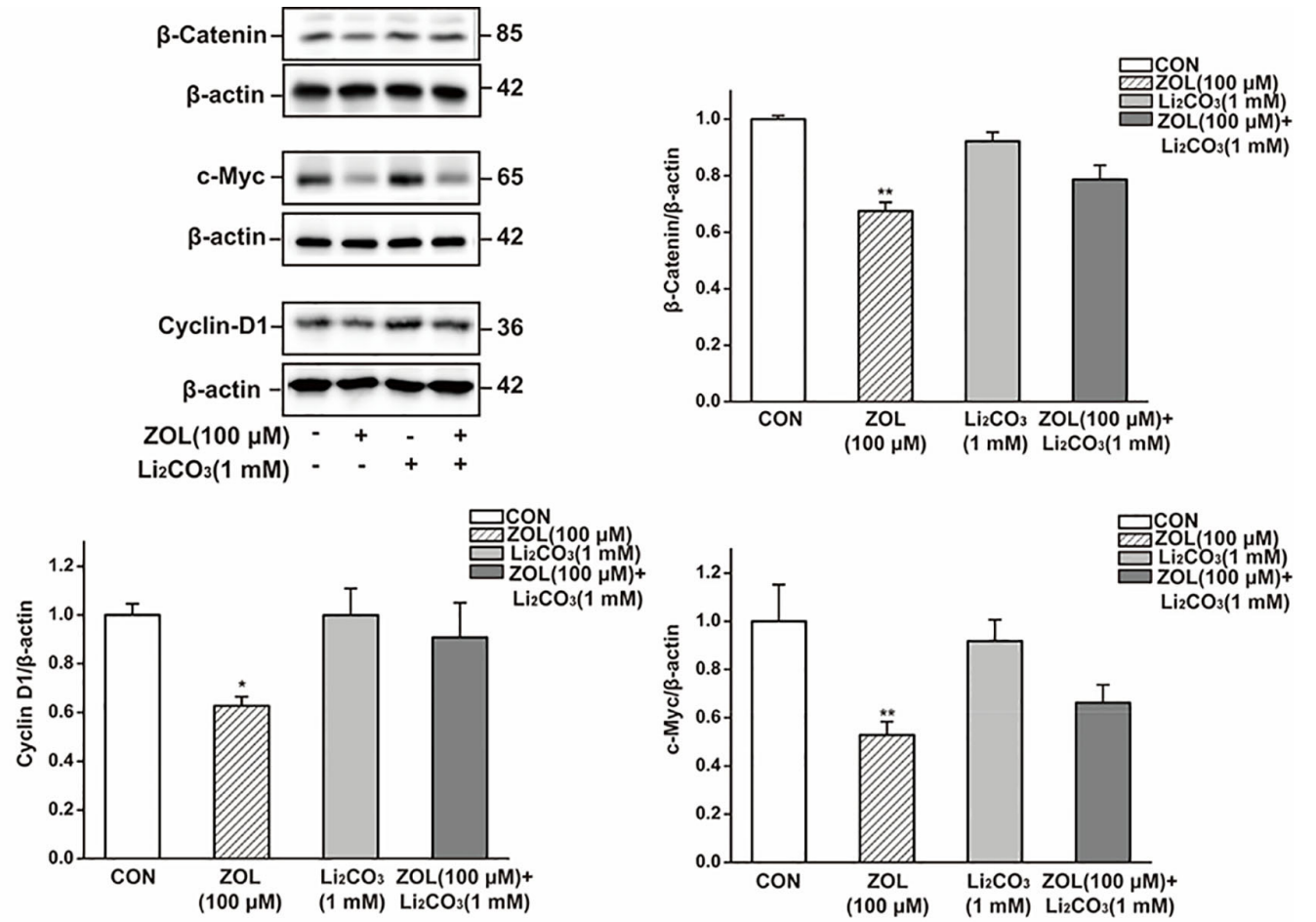

Figure 5. Effects of $\mathrm{ZOL}$ and $\mathrm{Li}_{2} \mathrm{CO}_{3}$ administration on the protein expression levels of $\beta$-Catenin, c-Myc and Cyclin D1 in U-2 OS cells. Data are presented as the mean \pm SEM of 3 separate experiments, ${ }^{* *}: \mathrm{p}<0.01$ and ${ }^{*}: \mathrm{p}<0.05$ vs. the CON group. 
A
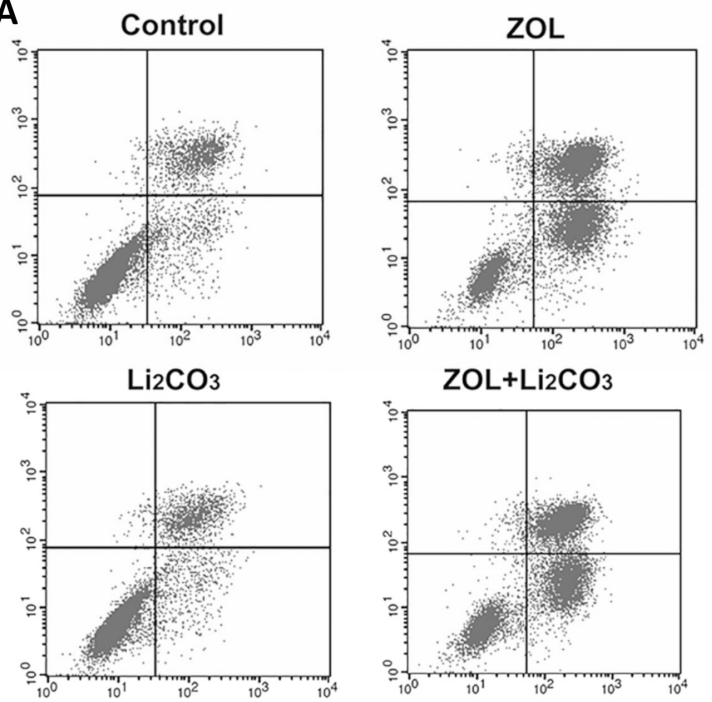

$\mathrm{ZOL}+\mathrm{Li}_{2} \mathrm{CO}_{3}$

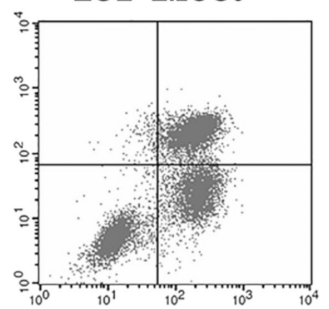

B

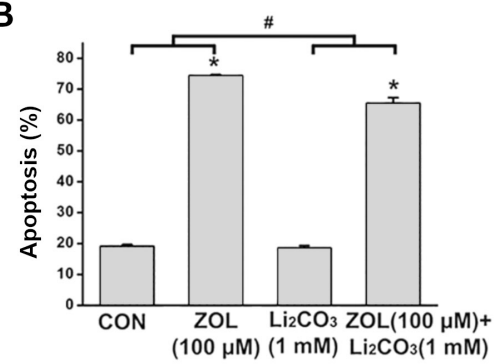

C

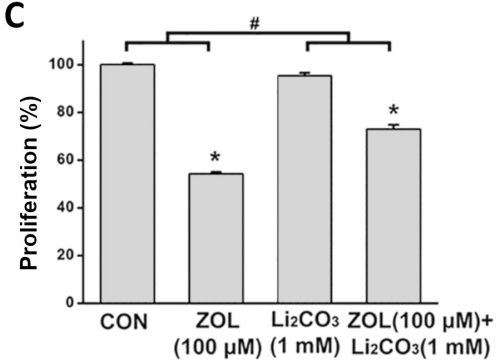

Figure 6. Effects of $\mathrm{ZOL}$ and $\mathrm{Li}_{2} \mathrm{CO}_{3}$ administration on MG-63 cell apoptosis as evaluated by flow cytometry (A), (B) and on cell proliferation using the MTT assay (C). Data are presented as the mean \pm SEM of 3 separate experiments, \#: p $<0.05$ indicates the difference between the $\mathrm{Li}_{2} \mathrm{CO}_{3}$ group and the $\mathrm{ZOL}+\mathrm{Li}_{2} \mathrm{CO}_{3}$ group vs. the difference between the $\mathrm{CON}$ group and the ZOL group, ${ }^{*}: \mathrm{p}<0.05$ indicates the difference between the $\mathrm{CON}$ group vs. the $\mathrm{ZOL}$ group or the difference between $\mathrm{Li}_{2} \mathrm{CO}_{3}$ vs. the $\mathrm{ZOL}+\mathrm{Li}_{2} \mathrm{CO}_{3}$ group.

\section{Discussion}

This study suggested that the effects of zoledronic acid (ZOL) on osteosarcoma (OS) cell lines are associated with AKT/GSK-3 $\beta$ and Wnt $/ \beta$-Catenin signaling. Our study found that $\mathrm{ZOL}$ induced apoptosis and inhibited the proliferation of the OS cell lines MG-63 and U-2 OS. The molecular mechanism behind the induce apoptosis response induced by $\mathrm{ZOL}$ is that activated AKT regulates the activity of downstream
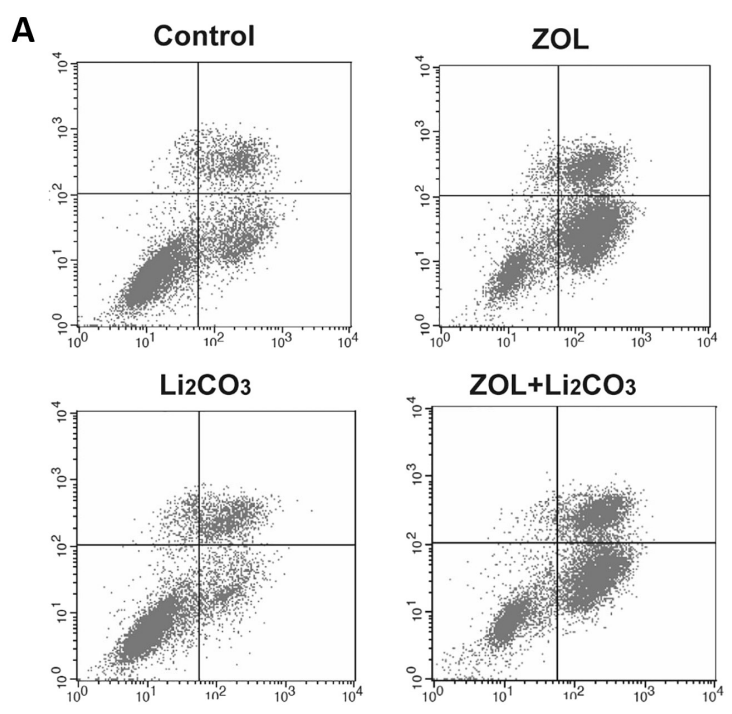

B

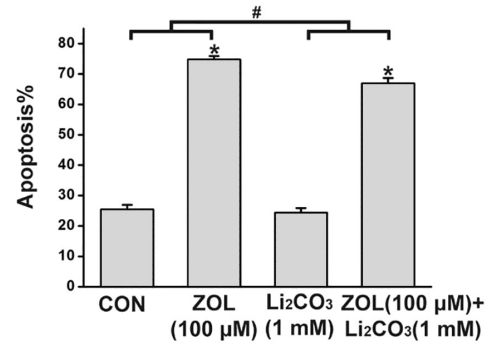

Figure 7. Effects of $\mathrm{ZOL}$ and $\mathrm{Li}_{2} \mathrm{CO}_{3}$ administration on $\mathrm{U}-2 \mathrm{OS}$ cell apoptosis as evaluated by flow cytometry. Data are presented as the mean \pm SEM of 3 separate experiments, \#: $\mathbf{p}<0.05$ indicates the difference between the $\mathrm{Li}_{2} \mathrm{CO}_{3}$ group and the $\mathrm{ZOL}+\mathrm{Li}_{2} \mathrm{CO}_{3}$ group vs the difference between the $\mathrm{CON}$ group and the ZOL group, ${ }^{*}: \mathrm{p}<0.05$ indicates the difference between the CON group vs the ZOL group, or the difference between $\mathrm{Li}_{2} \mathrm{CO}_{3}$ vs the $\mathrm{ZOL}+\mathrm{Li}_{2} \mathrm{CO}_{3}$ group.

target protein by activation or inhibition. As an important substrate of AKT, the activity of GSK-3 $\beta$ is negatively regulated by AKT. AKT inhibits glycogen synthesis by inhibiting GSK- $3 \beta$ phosphoglycogen synthase 1 . In our experiment, the expression of AKT and GSK-3 $\beta$ decreased after ZOL treatment of osteosarcoma cells, indicating that the change of AKT resulted in the decrease of GSK-3 $\beta$ protein expression and the increase of GSK-3 $\beta$ activity. In osteosarcoma cells, the degradation complex of $\beta$-Catenin (Axin/ APC/GSK-3 $\beta$ ) can inhibit the activity of GSK-3 $\beta$, thereby inhibiting the ubiquitination degradation of $\beta$-Catenin after phosphorylation, resulting in the stable accumulation of $\beta$-Catenin in the cytoplasm, increasing the expression of $\beta$-Catenin in the nucleus, binding with transcription factor LEF/TCF, initiating the transcription of target genes and increasing the expression of Cyclin D1 and c-Myc. It leads to the proliferation of osteosarcoma cells. However, when ZOL acts on osteosarcoma cells, GSK-3 $\beta$ activity increases which reduces the aggregation of $\beta$-Catenin nucleus and 

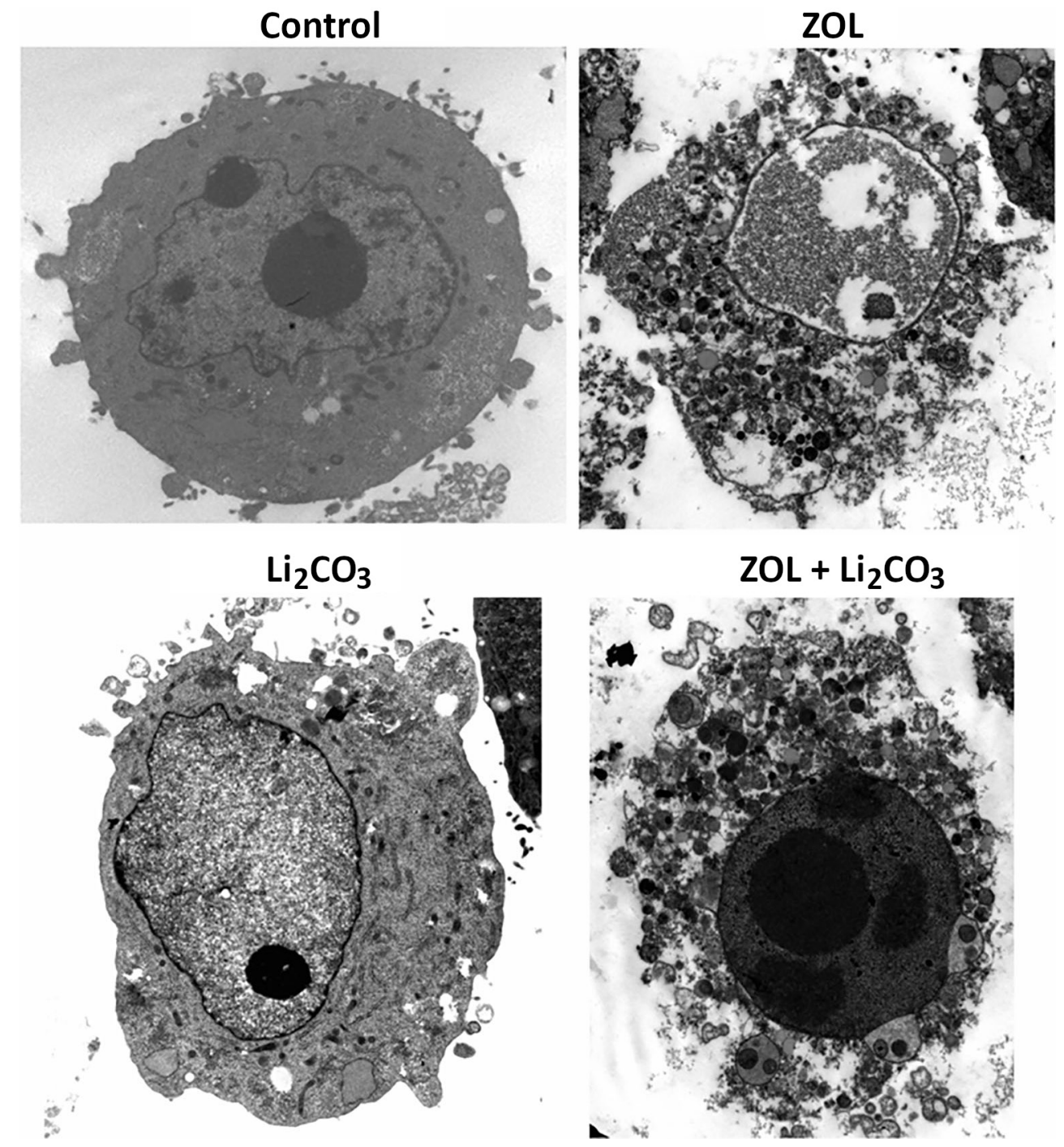

Figure 8. Effects of $\mathrm{ZOL}$ and $\mathrm{Li}_{2} \mathrm{CO}_{3}$ on MG-63 cell organelles as assessed with images obtained through an $\mathrm{H}-7650$ electron microscope.

inhibits the transcription of target genes, thus reducing the expression of Cyclin D1 and c-Myc. When GSK-3 $\beta$ inhibitor $\mathrm{Li}_{2} \mathrm{CO}_{3}$ was applied, the expression of $\beta$-Catenin, Cyclin D1 and $\mathrm{c}-\mathrm{Myc}$ increased partially which confirmed the abovementioned mechanism. The AKT/GSK-3 $\beta$ pathway and the $W n t / \beta$-Catenin pathway play important roles in the treatment effect of ZOL.

OS is one of the most common malignant tumors occurring during adolescence, with an incidence of 1-3 per 1 million people and a peak incidence at 18 years. The tumor develops rapidly, and the rate of malignancy is high; moreover, lung metastasis may occur during the early stage of this disease. The current treatments are mainly chemotherapy and surgery. The chemotherapy regimens for OS include high dosages of methotrexate (HD-MTX), doxorubicin (ADM), cisplatin (CDP) and ifosfamide (IFO).
ZOL is a third-generation nitrogen-containing bisphosphonate $(\mathrm{N}-\mathrm{BP})$, and it is a promising alternative treatment to OS. N-BP is a stable synthetic analog of endogenous pyrophosphate (PPi). N-BPs induce osteoclast apoptosis by inhibiting the mevalonate pathway enzymes, particularly farnesyl diphosphate synthase (FDP). ZOL is the most effective drug in clinical practice. It is one of the absorption inhibitors for the treatment of osteoporosis and other osteoclastmediated bone diseases, such as primary bone tumors. ZOL directly affects the proliferation and survival of OS tumor cells in vitro, which makes ZOL a potential treatment for OS, tumor cells and the bone microenvironment with high efficacy.

As we all know, MG-63 cell line is the most widely studied osteosarcoma cell line. In addition, the literature investigated the inhibitory effects of zoledronate on cell viability, motility, 
migration and invasion of 4 osteosarcoma cell lines (Saos2, MG-63, HOS and U-2 OS) by affecting cell morphology, epithelial-mesenchymal transition (EMT) and cytoskeletal organization as well as induction of E-cadherin and reduction of $\mathrm{N}$-cadherin with activation of transcription factors Slug and Twist. Taken together, zoledronate seemed to be the most potent in U-2 OS cells [17]. So, we chose MG-63 and U-2 OS as the model cell line for study. In this study, the results showed the effects of ZOL, including antiproliferative and proapoptotic, in the OS cell lines MG-63 and U-2 OS. We also identified that ZOL induced antiproliferative and proapoptotic activities by inhibiting the AKT/GSK-3 $\beta$ pathway, thereby decreasing Wnt pathway activation.

$\mathrm{ZOL}$ is used as a first-line agent in the conventional treatment to attenuate the development of skeletal metastases [18]. Mechanistically, the capacity of ZOL to impede malignant colonization of bones by cancer cells is attributed by its ability to reduce primary tumor growth and migration [19]. However, the role of ZOL in suppressing cancer cell dissemination remains controversial. In this study, we provide a scientific rationale to support the clinical application of ZOL in OS by evaluating the effects of ZOL treatments on OS cell survival and apoptosis, inhibition/activation of the AKT/ GSK- $3 \beta$ and Wnt signaling pathways.

The activation of the PI3K/AKT/GSK-3 $\beta$ pathway is thought to play a key role in cell death inhibition and cell cycle progression [20]. AKT has been shown to encourage G1/S cell cycle progression by inactivation of GSK-3 $\beta$ [21]. Moreover, $\mathrm{M}_{4} \mathrm{IDP}$, a ZOL derivative, inhibits the PI3K/AKT pathway, thereby increasing GSK-3 $\beta$ phosphorylation, which might be involved in the antitumor effects of $\mathrm{M}_{4} \mathrm{IDP}$ [14]. After treatment with ZOL, MG-63 cell proliferation was inhibited in both a dose- and time-dependent manner. The expression levels of $\mathrm{p}-\mathrm{AKT} / \mathrm{AKT}$ and $\mathrm{p}-\mathrm{GSK}-3 \beta / \mathrm{GSK}-3 \beta$ in MG-63 cells was also inhibited by ZOL in both a dose- and time-dependent manner, suggesting that the antiproliferative effect of ZOL might be caused by inhibition of the AKT pathway. In support of this conclusion, we observed similar results in U-2 OS cells.

The Wnt family has crucial functions in the regulation of cell proliferation, survival and migration [22]. This family has also been implicated in bone malignancies, osteogenic sarcoma or osteosarcoma. Wnt ligands and secreted Wnt inhibitors are expressed in human tumors and tumor cell lines. Knockdown of Wnt-related proteins, such as Secreted frizzled-related protein 2 (sFRP2) [23], Wnt inhibitory factor 1 (WIF1) [24], and Dickkopf-3 (Dkk3) [25], mitigates the metastatic and invasive phenotype. In the canonical Wnt pathway, Wnt causes an accumulation of the downstream target $\beta$-Catenin, which in the absence of Wnt ligands, is phosphorylated through a complex containing GSK-3 $\beta / A P C / A x i n$ and is then degraded. Our results suggested that ZOL treatment downregulated the expression of Wnt pathway-related proteins, such as $\beta$-Catenin, Cyclin D1 and c-Myc; however, inhibition of GSK-3 $\beta$ activation restored the expression levels of these proteins in MG-63 and U-2 OS cells. The results indicated that GSK-3 $\beta$ mediates ZOL-induced inhibition of the Wnt $/ \beta$-Catenin pathway. Furthermore, our results showed that treatment with a GSK-3 $\beta$ inhibitor rescued the apoptosis and inhibition of cell proliferation induced by ZOL, which suggested that inhibiting the Wnt/ $\beta$-Catenin pathway via GSK-3 $\beta$ activation might be involved in the antiproliferative and cytotoxic activities of ZOL.

In summary, our work demonstrated that ZOL possesses antiproliferative and cytotoxic activities in the human osteosarcoma cell lines MG-63 and U-2 OS by inducing apoptosis. Inhibition of the PI3K/AKT pathway could activate GSK-3 $\beta$ and downregulate the $\mathrm{Wnt} / \beta$-Catenin pathway which might be closely involved in these effects. These results provide a better understanding of the antitumor effects and the underlying mechanisms of ZOL.

Acknowledgments: The present study was supported by effect and molecular mechanism of miR-21 on gradient induced proliferation and differentiation of chondrocytes induced by gradient compressive stress (Liaoning Natural Science Foundation no. 201602836 Mr. Jianjun Li).

\section{References}

[1] CHANG J, WANG W, ZHANG H, HU Y, YIN Z. Bisphosphonates regulate cell proliferation, apoptosis and pro-osteoclastic expression in MG-63 human osteosarcoma cells. Oncology letters 2012; 4: 299-304. https://doi.org/10.3892/ ol.2012.723

[2] ORY B, BLANCHARD F, BATTAGLIA S, GOUIN F, REDINI F et al. Zoledronic acid activates the DNA S-phase checkpoint and induces osteosarcoma cell death characterized by apoptosis-inducing factor and endonuclease- $G$ translocation independently of p53 and retinoblastoma status. Mol Pharmacol 2007; 71: 333-343. https://doi.org/10.1124/ mol.106.028837

[3] HIRBE AC, ROELOFS AJ, FLOYD DH, DENG H, BECKER $\mathrm{SN}$ et al. The bisphosphonate zoledronic acid decreases tumor growth in bone in mice with defective osteoclasts. Bone 2009; 44: 908-916. https://doi.org/10.1016/j.bone.2009.01.010

[4] CLEZARDIN P1, FOURNIER P, BOISSIER S, PEYRUCHAUD O. In vitro and in vivo antitumor effects of bisphosphonates. Curr Med Chem 2003; 10: 173-180. https://doi.org/10.2174/0929867033368529

[5] GSCHWANTLER-KAULICH D, WEINGARTSHOFER S, GRUNT TW, MAIRHOFER M, TAN Y et al. Estradiol impairs the antiproliferative and proapoptotic effect of Zoledronic acid in hormone sensitive breast cancer cells in vitro. PLoS One 2017; 12: e0185566. https://doi.org/10.1371/journal.pone. 0185566

[6] RAO TP, KUHL M. An updated overview on Wnt signaling pathways: a prelude for more. Circ Res 2010; 106: 1798-1806. https://doi.org/10.1161/CIRCRESAHA.110.219840 
[7] MAO J, WANG J, LIU B, PAN W, FARR GH 3RD et al. Low-density lipoprotein receptor-related protein-5 binds to Axin and regulates the canonical Wnt signaling pathway. Mol Cell 2001; 7: 801-809. https://doi.org/10.1016/S10972765(01)00224-6

[8] CHEN C, ZHAO M, TIAN A, ZHANG X, YAO Z et al. Aberrant activation of $\mathrm{Wnt} /$ beta-catenin signaling drives proliferation of bone sarcoma cells. Oncotarget 2015; 6: 1757017583. https://doi.org/10.18632/oncotarget. 4100

[9] CAI Y, CAI T, CHEN Y. Wnt pathway in osteosarcoma, from oncogenic to therapeutic. J Cell Biochem 2014; 115: 625631. https://doi.org/10.1002/jcb.24708

[10] PERRY JA, KIEZUN A, TONZI P, VAN ALLEN EM, CARTER SL et al. Complementary genomic approaches highlight the PI3K/mTOR pathway as a common vulnerability in osteosarcoma. Proc Natl Acad Sci U S A 2014; 111: E5564-5573. https://doi.org/10.1073/pnas.1419260111

[11] MORIARITY BS, OTTO GM, RAHRMANN EP, RATHE SK, WOLF NK et al. A Sleeping Beauty forward genetic screen identifies new genes and pathways driving osteosarcoma development and metastasis. Nat Genet 2015; 47: 615-624. https://doi.org/10.1038/ng.3293

[12] THIELE S, RAUNER M, GOETTSCH C, RACHNER TD, BENAD P et al. Expression profile of WNT molecules in prostate cancer and its regulation by aminobisphosphonates. J Cell Biochem 2011; 112: 1593-1600. https://doi. org/10.1002/jcb. 23070

[13] LAN YC, CHANG CL, SUNG MT, YIN PH, HSU CC et al. Zoledronic acid-induced cytotoxicity through endoplasmic reticulum stress triggered REDD1-mTOR pathway in breast cancer cells. Anticancer Res 2013; 33: 3807-3814.

[14] PENG Y, QIU L, XU D, ZHANG L, YU H et al. M4IDP, a zoledronic acid derivative, induces G1 arrest, apoptosis and autophagy in HCT116 colon carcinoma cells via blocking PI3K/Akt/mTOR pathway. Life Sci 2017; 185: 63-72. https:// doi.org/10.1016/j.lfs.2017.07.024

[15] TAI TW, CHEN CY, SU FC, TU YK, TSAI TT et al. Reactive oxygen species are required for zoledronic acid-induced apoptosis in osteoclast precursors and mature osteoclastlike cells. Sci Rep 2017; 7: 44245. https://doi.org/10.1038/ srep 44245
[16] LIU Y, LIU YZ, ZHANG RX, WANG X, MENG ZJ et al. Oridonin inhibits the proliferation of human osteosarcoma cells by suppressing Wnt/beta-catenin signaling. Int J Oncol 2014; 45: 795-803. https://doi.org/10.3892/ijo.2014.2456

[17] CHENG HL, LIN CW, YANG JS, HSIEH MJ, YANG SF et al. Zoledronate blocks geranylgeranylation not farnesylation to suppress human osteosarcoma U2OS cells metastasis by EMT via Rho A activation and FAK-inhibited JNK and p38 pathways. Oncotarget 2016; 7: 9742-9758. https://doi. org/10.18632/oncotarget.7138

[18] BERENSON JR. Zoledronic acid in cancer patients with bone metastases: results of Phase I and II trials. Semin Oncol 2001; 28: 25-34.

[19] DASS CR, CHOONG PF. Zoledronic acid inhibits osteosarcoma growth in an orthotopic model. Mol Cancer Ther 2007; 6: 3263-3270. https://doi.org/10.1158/1535-7163.MCT-070546

[20] KAWASAKI A, TORII K, YAMASHITA Y, NISHIZAWA K, KANEKURA $\mathrm{K}$ et al. Wnt5a promotes adhesion of human dermal fibroblasts by triggering a phosphatidylinositol-3 kinase/Akt signal. Cell Signal 2007; 19: 2498-2506. https://doi. org/10.1016/j.cellsig.2007.07.023

[21] LIANG J, SLINGERLAND JM. Multiple roles of the PI3K/ PKB (Akt) pathway in cell cycle progression. Cell Cycle 2003; 2: 339-345.

[22] NUSSE R, VARMUS H. Three decades of Wnts: a personal perspective on how a scientific field developed. EMBO J 2012; 31: 2670-2684. https://doi.org/10.1038/emboj.2012.146

[23] ENDO Y, BEAUCHAMP E, WOODS D, TAYLOR WG, TORETSKY JA et al. Wnt-3a and Dickkopf-1 stimulate neurite outgrowth in Ewing tumor cells via a Frizzled3- and cJun N-terminal kinase-dependent mechanism. Mol Cell Biol 2008; 28: 2368-2379. https://doi.org/10.1128/MCB.01780-07

[24] BAKER EK, TAYLOR S, GUPTE A, CHALK AM, BHATTACHARYA $S$ et al. Wnt inhibitory factor 1 (WIF1) is a marker of osteoblastic differentiation stage and is not silenced by DNA methylation in osteosarcoma. Bone 2015; 73: 223-232. https://doi.org/10.1016/j.bone.2014.12.063

[25] HOANG BH, KUBO T, HEALEY JH, YANG R, NATHAN SS et al. Dickkopf 3 inhibits invasion and motility of Saos2 osteosarcoma cells by modulating the Wnt-beta-catenin pathway. Cancer Res 2004; 64: 2734-2739. https://doi. org/10.1158/0008-5472.CAN-03-1952 